\title{
Distribution of Complex and Core Lipids within New Hyperthermophilic Members of the Archaea Domain
}

\author{
ANTONIO TRINCONE ${ }^{1}$, BARBARA NICOLAUS ${ }^{1}$, GIANNA PALMIERI ${ }^{1}$, MARIO DE ROSA $^{2}$, ROBERT \\ HUBER $^{3}$, GERTRUD HUBER ${ }^{3}$, KARL OTTO STETTER ${ }^{3}$, and AGATA GAMBACORTA ${ }^{1}$ \\ 1 Istituto per la Chimica di Molecole di Interesse Biologico, Arco Felice, Napoli, Italy \\ 2 Istituto di Biochimica delle Macromolecole Facolta' Medicina, Napoli, Italy \\ 3 Lehrstuhl für Mikrobiologie, Universität Regensburg, 8400 Regensburg, Germany
}

Received June 27, 1991

\begin{abstract}
Summary
Core and complex lipids of several new hyperthermophilic archaeal isolates were analyzed. The organisms belong to the Sulfolobales, Archaeoglobus, Pyrobaculum, and Methanococcus. A detailed structural investigation of complex lipids of Pyrobaculum species is reported. The different lipid structures are of help for a rapid and simple phylogenetic classification of the new isolates. They are in agreement with the classification based on other features.
\end{abstract}

Key words: Archaea - Hyperthermophilic - Lipids - Isopranyl ether

\section{Introduction}

The archaeal domain of life had been discovered and its phylogenetic relationship had been investigated by comparison of $16 \mathrm{~S}$ rRNA catalogues and total sequences (Woese, et al., 1978; Woese et al., 1990). It comprises many phylogenetically and physiologically diverse groups with distinct features. Within the Archaea, two phylogenetic domains are evident: (1) the Euryarchaeota containing the methanogens, extreme halophiles, the cell-wall deficient organotrophic Thermoplasma, the sulfate reducing Archaeoglobus, and the organothrophic Thermococcales, and (2) the Crenarchaeota comprising the sulfur-metabolizing genera Pyrodictium, Desulfurococcus, Staphylothermus, Thermodiscus, Hyperthermus, Thermoproteus, Pyrobaculum, Thermofilum, Sulfolobus, Acidianus, Desulfurolobus, and Metallosphaera (Stetter et al., 1990). Hyperthermophiles with optimal growth temperatures between 80 and $110^{\circ} \mathrm{C}$ are so far members of the genera Methanococcus (only M. jannaschii and M. igneus), Methanothermus, Methanopyrus, Archaeoglobus, Thermococcus, Pyrococcus, and of all the genera of the subdomain Crenarchaeota. Archaeoglobus represents a biochemical missing link between the methanogens and the sulfur-metabolizing archaea (Achenbach-Richter et al., 1987). Acidianus and its close relative Desulfurolobus rep- resent a missing biochemical link between the sulfur-oxidizing and sulfur-reducing archaea (Segerer et al., 1985; Segerer et al., 1986; Zillig et al., 1986; Huber et al., 1987).

All archaeal membrane lipids isolated to date are based on isopranyl glycerol ethers in contrast to the fatty acid glycerol esters usual in bacteria. Many of their unusual structural features can be considered to be specific taxonomic markers of this group of microorganisms. The complex lipids of archaea are based on two classes of isopranoid ether core lipids: diethers and tetraethers. The former is structurally derived from glycerol in which the oxygens in 2- and 3-sn positions are linked via ether link to $\mathrm{C}_{20}$ or $\mathrm{C}_{25}$ isopranoid alcohol. The 2,3-di-O-phytanylsn-glycerol a (Fig. 1) could be considered a universal core lipid in archaea. This glycerol diether represents $100 \%$ of ether core lipids in the majority of neutrophilic halophiles and in some coccoid forms belonging to methanogens and thermophiles (De Rosa et al., 1991).

A macrocyclic glycerol diether b (Fig. 1), characterized by the presence of a 36 membered ring originated from the condensation of a glycerol with a $\mathrm{C}_{40} \omega-\omega^{\prime}$ ' isopranyl diol, is found until now in Methanococcus jannaschii and this lipid characterizes this species (Comita et al., 1984).

Other structural varieties are found among archaeal 
<smiles>CC(C)CCC[C@H](C)CCC[C@H](C)CCC[C@H](C)CCC[C@@H](C)CCC[C@@H](C)CC[C@H](C)CCCO[C@H](C)CO</smiles>

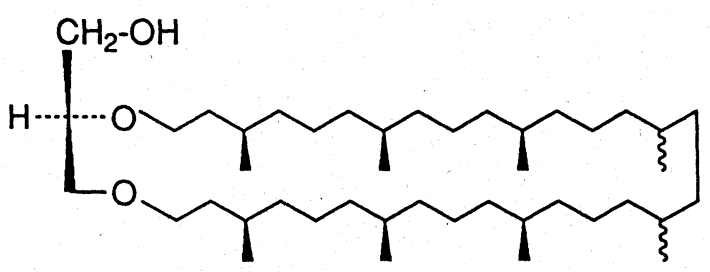

Fig. 1. Glycerol diethers. $a=2,3-$ di-O-phytanyl-sn-glycerol. $b=$ macrocyclic diether.

diethers such as substitution of glycerol with tetritol in a unique lipid found in Methanosarcina barkeri and different alkyl chains such as sesterterpanyl $\left(\mathrm{C}_{25}\right)$ or phytanyl $\left(\mathrm{C}_{20}\right)$ with a $\mathrm{OH}$ group in the position 3 found in alkaliphilic halophiles and in Methanothrix concilii GP6, respectively, (Ferrante et al., 1988; De Rosa et al., 1989).

The tetraethers found in the archaea are classified in two series: in the first series, a tetraether molecule has a 72-member ring formed by two 2,3-sn-glycerol moieties bridged through ether linkages by two isopranoid $\mathrm{C}_{40}$ diols formally derived from head to head linkage of two O-phytanyl residues. The presence of differently cyclized $\mathrm{C}_{40}$ diols originates a series of nine compounds named GDGTs (glycerol dialkyl glycerol tetraethers). The second series has a structural organization similar to that of GDGTs, but a more complex polyol with nine carbon atoms replaces one of the glycerols. By analogy this series is named GDNTs (glycerol dialkyl nonitol tetraethers; $D e$ Rosa et al., 1983). The uncyclized GDGT a (Fig. 2) and 2,3-di-O-phytanyl-sn-glycerol in different proportions are the basic components of complex lipids of methanogenic archaea belonging to the orders Methanobacteriales and Methanomicrobiales. Only in Ms. barkeri and in Mt. sociabilis tetraethers with cyclopentane rings are detected (Trincone et al., 1988). Tetraethers are the main components of lipids of Crenarchaeota, moreover the presence of the lipids based on GDNTs characterizes the microorganisms belonging to the Sulfolobales order.

The complex lipids of archaea are identified as phospho-, phosphoglyco-, amino-, aminophospho-, and glycolipids by the use of specific staining tests and by spectroscopic and chemical procedures. Aminolipids and aminophospholipids were found to be widely distributed in methanogens in which they prevail in contrast with the other two phenotypes (De Rosa et al., 1991). Usually in thermophilic archaea the polar lipids are based on tetraethers. Glycolipids are present in lesser amount than acidic lipids. Phospholipids and phosphoglycolipids contain usually inositol as head group. Moreover only in the thermophiles belonging to the genera Thermococcus, $P y$ - rococcus and in AN1 isolate are found complex lipids based on 2,3-di-O-phytanyl-sn-glycerol.

In this paper we describe the core and the complex lipids of several new hyperthermophilic archaeal isolates belonging to the Sulfolobales, Archaeoglobus, Pyrobaculum and Methanococcus.

\section{Materials and Methods}

Cultivation of strains. Strains of hyperthermophilic Archaea were grown in 3001 batch cultures using an enamel-protected fermentor (HTE, Bioengineering, Wald, Switzerland). Metallosphaera sedula, TH2 and Sp3a the same as the isolates VE2, VE6 and HVS were cultivated aerobically on $S^{\circ}(1 \%)$ and yeast extract $(0.02 \%)$ in modified Allen medium (Allen, 1959; Huber et al., 1989). Sulfolobus metallicus strains Kra22 and Kra23 were grown autotrophically in modified Allen medium in the presence of $S^{\circ}(1 \%)$. Pyrobaculum organotrophum and $P$. islandicum were grown anaerobically on modified Allen medium as described (Huber et al., 1987). Archaeoglobus fulgidus VC16 and Archaeoglobus profundus AV18 and Kol3 were grown on modified Wolfe's medium 3 (Balch et al., 1979; Stetter et al., 1987; Stetter, 1988; Burggraf et al., 1990 a). Methanococcus igneus Kol5 was grown chemolithoautotrophically on modified Wolfe's medium 3 with $\mathrm{H}_{2} / \mathrm{CO}_{2}$ as gas phase (Burggraf et al., $1990 \mathrm{~b}$ ).

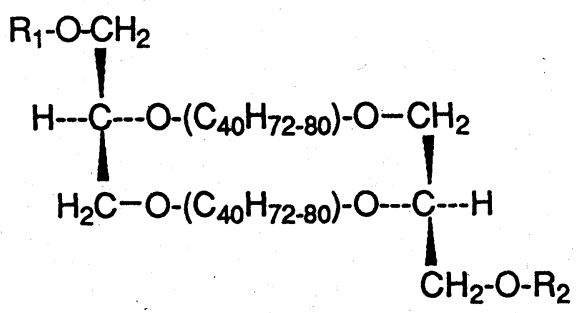

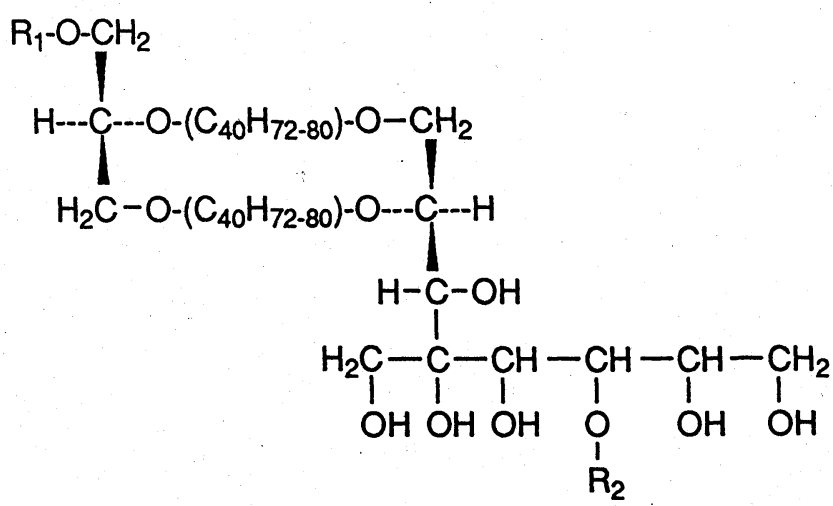

Fig. 2. a. $R_{1}=R_{2}=H$, GDGT (differently cyclized glycerol dialkylglycerol tetraethers) $a-i$

$\mathrm{R}_{1}=\mathrm{H} ; \mathrm{R}_{2}=\beta$-D-glc $p \rightarrow \beta$-D-gal $p \quad \mathrm{GLI}$

$R_{1}=$ phosphoinositol; $R_{2}=H$ PLI

$R_{1}=$ phosphoinositol; $R_{2}=\beta$-D-glc $p \rightarrow \beta$-D-galp PGLI .

b. $\mathrm{R}_{1}=\mathrm{R}_{2}=\mathrm{H}$, GDNT (glycerol dialkylnonitol tetraethers) $a^{\prime}-i^{\prime}$

$\mathrm{R}_{1}=\mathrm{H} ; \mathrm{R}_{2}=\beta$-D-glc $p$ GLII

$R_{1}=H ; R_{2}=\beta$-D-glcp-sulfate SGLII

$\mathrm{R}_{1}=$ phosphoinositol; $\mathrm{R}_{2}=\beta$-D-glcp PGLII 
- Thermoproteus tenax was generously given by Prof. W.Zillig, Max Planck Institute.

Extraction of lipids. Lyophilized cells were extracted continuously (Soxhlet), first for $15 \mathrm{~h}$ with $\mathrm{CHCl}_{3} / \mathrm{MeOH}(1: 1, \mathrm{v} / \mathrm{v})$ and then with $\mathrm{MeOH} / \mathrm{H}_{2} \mathrm{O}(1: 1, \mathrm{v} / \mathrm{v})$. The combined extracts were dried under vacuum and dissolved in $\mathrm{CHCl}_{3} / \mathrm{MeOH}(1: 1, \mathrm{v} / \mathrm{v})$. The soluble material represented total lipid extract. Quinone extraction was performed by treating total lipid extract with light petroleum b.p. $40-70^{\circ} \mathrm{C}$, the soluble fraction represented the quinone extract.

Fractionation of the lipid. The total lipid extract of Pyrobaculum organotrophum and $P$. islandicum was dissolved in $\mathrm{CHCl}_{3} / \mathrm{MeOH} / \mathrm{H}_{2} \mathrm{O}$ (65:25:4, by vol.) mixed with $5 \mathrm{~g}$ of silica gel (Merck Kieselgel 70-230 mesh) and dried. Dried material was applied to the top of a silica-gel column $(30 \mathrm{~cm}, 10 \mathrm{~mm}$ i.d.) and then eluted with 31 of a step gradient of $0-50 \%(\mathrm{v} / \mathrm{v}) \mathrm{MeOH}$ in $\mathrm{CHCl}_{3}$ in $5 \%$ increments $(250 \mathrm{ml}$ for each gradient step). All the lipids eluted were further purified by preparative TLC in $\mathrm{CHCl}_{3} /$ $\mathrm{MeOH} / \mathrm{H}_{2} \mathrm{O}$ (65:25:4, by vol.).

Chemical procedures. Total lipid extracts or purified complex lipids were hydrolyzed with methanolic $\mathrm{HCl}$ (1N at reflux for 3 h). The hydrolysis mixture was dried in vacuum and then dissolved in $\mathrm{CHCl}_{3} / \mathrm{H}_{2} \mathrm{O}(1: 1, \mathrm{v} / \mathrm{v})$ yielding a biphasic system; the $\mathrm{CHCl}_{3}$-soluble and the $\mathrm{H}_{2} \mathrm{O}$-soluble material were analyzed chromatographically.

Mild acid hydrolysis was performed by treating the lipid material with $0.5 \mathrm{~N}$ methanolic $\mathrm{HCl}$ at room temperature. The hydrolysis mixture was dried in vacuum and then analyzed by TLC.

Alkaline hydrolysis was performed by treating the lipid material with $1 \mathrm{~N} \mathrm{NaOH}$ for $3 \mathrm{~h}$ at $87^{\circ} \mathrm{C}$. The dried hydrolysis mixture was dissolved in $\mathrm{CHCl}_{3} / \mathrm{MeOH} / \mathrm{H}_{2} \mathrm{O}(65: 25: 4$, by vol.) and analyzed by TLC.

Permethylation was made with dimethylformamide $/ \mathrm{NaH} /$ $\mathrm{CH}_{3} \mathrm{I}$ as previously described (Yahara et al., 1977).

Acetylation of isoprenoid ether was performed with $\mathrm{Ac}_{2} \mathrm{O} / \mathrm{py}-$ ridine $(9: 1, \mathrm{v} / \mathrm{v})$ under reflux for $6 \mathrm{~h}$.

Chromatographic procedures. Thin layer chromatography (TLC) was performed on $0.25 \mathrm{~mm}$ layers of silica gel F254, Merck activated at $100{ }^{\circ} \mathrm{C}$ for $2 \mathrm{~h}$. Solvents included $\mathrm{CHCl}_{3} /$ $\mathrm{MeOH} / \mathrm{H}_{2} \mathrm{O}$ (65:25:4, by vol.) for complex lipids; $\mathrm{CHCl}_{3} / \mathrm{Et}_{2} \mathrm{O}$ $(9: 1, \mathrm{v} / \mathrm{v})$ for 2,3-di-O-phytanyl-sn-glycerol; n-hexane-EtOAc $\left(75: 25\right.$, v/v) for glycerol dialkyl glycerol tetraethers; $\mathrm{CHCl}_{3}$ / $\mathrm{MeOH}(9: 1, \mathrm{v} / \mathrm{v})$ for glycerol dialkyl nonitol tetraethers; n$\mathrm{BuOH} / \mathrm{CH}_{3} \mathrm{COOH} / \mathrm{H}_{2} \mathrm{O}(60: 20: 20$, by vol.) for myo-inositol, phosphomyo-inositol and glucose. Compounds were detected either by exposure to $\mathrm{I}_{2}$ vapour, or by spraying with $0.1 \%$ $\mathrm{Ce}\left(\mathrm{SO}_{4}\right)_{2}$ in $2 \mathrm{~N} \mathrm{H}_{2} \mathrm{SO}_{4}$ followed by heating at $150^{\circ} \mathrm{C}$ for $5 \mathrm{~min}$. Specific reagents included the Dittmer and Lester reagent for phospholipids, $\alpha$-naphtol/ $/ \mathrm{H}_{2} \mathrm{SO}_{4}$ for glycolipids (Dittmer and Lester, 1964; Kates, 1972) and ninhydrin reagent for aminolipids. HPLC of the water soluble hydrolyzate was done on a Carbohydrate Analysis column ( $30 \mathrm{~cm} \times 3.9 \mathrm{~mm}$ i.d.) using as solvent $\mathrm{CH}_{3} \mathrm{CN} / \mathrm{H}_{2} \mathrm{O}(80: 20, \mathrm{v} / \mathrm{v})$ at a flow rate of $1 \mathrm{ml} / \mathrm{min}$; HPLC of $\mathrm{CHCl}_{3}$ soluble hydrolyzate was done on a $\mu$-Porasil column $(30 \mathrm{~cm} \times 3.9 \mathrm{~mm}$ i.d. $)$ using as solvent $\mathrm{n}$-hexane-EtOAc $(80: 20, \mathrm{v} / \mathrm{v})$ for 2,3-di-O-phytanyl-sn-glycerol; n-hexane-EtOAc $(60: 40, \mathrm{v} / \mathrm{v})$ for GDGTs. All HPLC analyses were made on a Waters Associates apparatus and eluants from column were detected with differential refractometer.

GLC-MS analysis of permethylated sugars was carried out on a glass column $(2 \mathrm{~m} \times 2 \mathrm{~mm}$ i.d. $)$ packed with $20 \%$ butan-1,4diol succinate on Chromosorb WAW, column temp. $155^{\circ} \mathrm{C}, \mathrm{N}_{2} 1$ $\mathrm{kg} / \mathrm{cm}^{2}$ (Yahara et al., 1977).

Purification of isoprenoid ether component. The chloroform soluble fraction of the hydrolysis mixture was chromatographed over a silica-gel column eluting with chloroform for diethers,
$\mathrm{CHCl}_{3} / \mathrm{Et}_{2} \mathrm{O}(9: 1 \mathrm{v} / \mathrm{v})$ for GDGTs, and $\mathrm{CHCl}_{3} / \mathrm{MeOH}(9: 1, \mathrm{v} / \mathrm{v})$ for GDNTs.

NMR and mass spectroscopy. NMR spectra were run at 500 $\mathrm{MHz}\left({ }^{1} \mathrm{H}\right.$ NMR) and $125 \mathrm{MHz}\left({ }^{13} \mathrm{C}\right.$ NMR) on a Bruker WH-500 spectrometer. The spectra were run in $\mathrm{CDCl}_{3} / \mathrm{CD}_{3} \mathrm{OD}(7: 3, \mathrm{v} / \mathrm{v})$. Multiplicities of the signals were determined by DEPT experiments.

The MS measurements in electron impact were performed at $70 \mathrm{eV}$ with the A.E.I. MS-50 spectrometer.

\section{Results}

Core lipids obtained after acid hydrolysis of total lipid extracts were identified as follows: 2,3-di-O-phytanyl-snglycerol (HPLC, EI-MS of acetylated derivative and $[\alpha]_{\mathrm{D}}^{20}$ value); GDGTs and GDNTs (TLC, ${ }^{13} \mathrm{C}$ NMR and $[\alpha]_{D}^{20}$ value).

Complex lipids of the isolates belonging to the Sulfolobales order, Archaeoglobus and Methanococcus genera have been analyzed by comparison with complex lipids of known species. Complex lipids of $P$. organotrophum and $P$. islandicum have been analyzed by chemical and spectroscopic methods.

Identification of the quinones in the microorganisms belonging to the Sulfolobales order has been made by EI-MS analysis while their relative percentages have been calculated by integration peak areas in HPLC.

\section{Sulfolobales order}

Seven new isolates of thermophilic archaea were analyzed for their lipid composition. They were named: VE2, Kra22, VE6, SP3a, Kra23, TH2, and HV5. The quinone composition of the isolates and of other microorganisms belonging to the Sulfolobales order is shown in Table 1. All the isolates analyzed possess caldariellaquinone, a unique benzothiophenquinone present as major component of the quinone fraction of Sulfolobus solfataricus. Only in

Table 1. Comparison of quinone composition among new isolates and other organisms belonging to Sulfolobales order

\begin{tabular}{lrcc}
\hline Species & CQ & SQ & SSQ \\
\hline TH2 & 100 & - & - \\
SP3a & 100 & - & - \\
Kra22 & 100 & - & - \\
Kra23 & 100 & - & - \\
VE6 & 95 & 5 & - \\
VE2 & 100 & - & - \\
HV5 & 100 & - & - \\
S. solfataricus & 94 & 5 & 0.2 \\
D. ambivalens (a) & 83 & 16 & trace \\
D. ambivalens (an) & - & 99 & - \\
\hline
\end{tabular}

$\mathrm{CQ}=$ Caldariellaquinone (see text)

$\mathrm{SQ}=$ Sulfolobusquinone (see text)

SSQ = Tricyclicquinone (De Rosa and Gambacorta, 1988)

a = grown under aerobiosis

an $=$ grown under anaerobiosis 


\begin{tabular}{|c|c|c|c|c|c|c|c|c|}
\hline $\mathrm{GDGT}^{\mathrm{a}}$ & TH2 & Kra23 & $\mathrm{SP} 3 \mathrm{a}$ & VE6 & HV5 & VE2 & $\mathrm{Kra} 22$ & $\begin{array}{l}\text { S. sol- } \\
\text { fataricus }\end{array}$ \\
\hline $\begin{array}{ll}\text { a } & 0 \\
\text { b } & 1 \\
\text { c } & 2 \\
\text { d } & 3 \\
\text { e } & 4 \\
\text { f } & 5 \\
\text { g } & 6 \\
\text { h } & 7 \\
\text { i } & 8\end{array}$ & $\begin{array}{l}+ \\
+ \\
+ \\
+ \\
+\end{array}$ & $\begin{array}{l}- \\
+ \\
++ \\
+ \\
-\end{array}$ & $\begin{array}{l}+ \\
+ \\
++ \\
+++ \\
+++\end{array}$ & $\begin{array}{l}+ \\
+ \\
+ \\
++ \\
+++ \\
++ \\
+\end{array}$ & $\begin{array}{l}+ \\
+ \\
++ \\
++ \\
++\end{array}$ & $\begin{array}{l}+ \\
+ \\
++ \\
++ \\
++\end{array}$ & $\begin{array}{l}+ \\
++ \\
++ \\
+ \\
+\end{array}$ & $\begin{array}{l}+ \\
+ \\
+ \\
++ \\
+++ \\
++++ \\
+++ \\
++ \\
+\end{array}$ \\
\hline
\end{tabular}

a The number represents the cyclopentane rings in the molecule. For the structure see Fig. 2 compounds a-i.

b Trincone et al. 1989.

VE6 sulfolobusquinone is present in the same proportion as in $S$. solfataricus.

Total lipids from these thermophilic isolates account for about $7-8 \%$ of dried cells. All the isolates show a pattern of complex lipids very close to that reported for $S$. solfataricus (Fig. 2). However the relative proportions of glycolipids GL-I and GL-II (Fig. 2) are different as judged by TLC. Hydrolysis of complex lipids of the isolates gives rise to a mixture of GDGTs and GDNTs and to trace amounts of 2,3-di-O-phytanyl-sn-glycerol. The analysis of cyclic composition of GDGTs performed by TLC as previously reported (Trincone et al., 1988) shows all isolates possess cyclized tetraethers as reported in Table 2.

\section{Archaeoglobus genus}

To date Archaeoglobus is represented by two species Archaeoglobus fulgidus VC16 DSM 4304 and Archaeoglobus profundus AV18 DSM 5681.

The two species of Archaeoglobus genus and an isolate Kol3 are analyzed for their lipid composition.

Core lipids of both species of Archaeoglobus are based on 2,3-di-O-phytanyl-sn-glycerol and tetraether a (Fig. 2). The former is present only in trace amounts in the isolate Kol3. However, A. fulgidus and A. profundus are different in the composition of complex lipids as judged by staining tests at TLC level. In A. fulgidus, two phosphoglycolipids at $\operatorname{Rf} 0.10$ and 0.25 , one phospholipid at $\mathrm{Rf} 0.30$ and one glycolipid at $\mathrm{Rf} 0.60$ are present as major complex lipids. In AV18 the major complex lipids are two phosphoglycolipids at $\mathrm{Rf} 0.10$ and 0.13 and four glycolipids at $\mathrm{Rf}$ $0.40,0.45,0.60$ and 0.65 . The pattern of complex lipids in the isolate Kol3 appears to be the same as for AV18. In all isolates of the Archaeoglobus genus examined so far aminolipids are absent.

\section{Pyrobaculum genus}

Pyrobaculum islandicum (DSM 4184), a facultative autotrophic archaeon, which is the type species of a new genus of hyperthermophilic archaea, and Pyrobaculum organotrophum (DSM 4185) that is obligately heterotrophic, are analyzed in detail for their lipid composition.

Core lipids of Pyrobaculum species are restricted to tetraether of GDGT type and trace amounts of 2,3-di-Ophytanyl-sn-glycerol. Analysis of cyclization of GDGTs, performed by TLC (Trincone et al., 1988) shows the presence of tetraethers a-e (Fig. 2) in different proportions in both organisms. The more cyclized products, $\mathrm{d}$ and $\mathrm{e}$ are found to be the major components in Pyrobaculum organotrophum, while less cyclized tetraethers a-c (Fig. 2) are more abundant in Pyrobaculum islandicum.

In Table 3 is reported the composition of complex lipids from these two organisms. Both possess glyco- and phos-

\begin{tabular}{lllllll}
\hline Rf & 0.05 & 0.16 & 0.20 & 0.30 & 0.60 & 0.80 \\
\hline Pyrobaculum islandicum & GPL-I & GPL-II & GL-I & GL-II & GL-III & GL-IV \\
$\begin{array}{l}\text { Relative proportions } \\
\text { (\% of total lipid weight) }\end{array}$ & 30 & 35 & 7 & 15 & 3 & 10 \\
$\begin{array}{l}\text { Pyrobaculum organotrophum } \\
\begin{array}{l}\text { Relative proportions } \\
\text { (\% of total lipid weight) }\end{array}\end{array}$ & GPL-I & GPL-II & PL-I & GL-II & GL-III & GL-IV \\
\hline
\end{tabular}

Table 3. Rf, staining tests and relative proportions of complex lipids in Pyrobaculum spp.

$\mathrm{G}=\alpha$-naphthol positive

$\mathrm{P}=$ phosphorus positive 
Table 4. Main differenices in the downfield part of ${ }^{13} \mathrm{C}$ NMR spectra of lipids of Pyrobaculum species

\begin{tabular}{llllll}
\hline Glycerol units & & GL-IV & GPL-II & GL-II & GPL-I \\
\hline Glycosylated & & & & & \\
& C-1 & 70.9 & as in & as in & as in \\
& C-2 & 78.0 & GL-IV & GL-IV & GPL-II \\
& C-3 & 70.2 & & & \\
Free or -P & & & & & as in \\
& C-1 & 62.0 & 65.3 & as in & GPL-II \\
& C-2 & 78.0 & 77.8 & GL-IV & \\
P-myo-inositol & C-3 & 70.2 & 70.0 & & \\
& & & & & \\
& P-O-C & & 72.5 & & as in \\
& & & 71.4 & & \\
\hline & & & 71.3 & & \\
\hline
\end{tabular}

phoglycolipids being the sole difference the presence of a phopspholipid at Rf 0.20 in P. organotrophum instead of the glycolipid at the same $\mathrm{Rf}$ found in $P$. islandicum. Aminophospholipids are absent in both organisms.

In Table 4 is reported the downfield part of the ${ }^{13} \mathrm{C}$ NMR spectra of four major complex lipids that account for $85 \%$ of total lipids of both organisms.

GL-IV ( $R f 0.80$ ) is a monoglycolipid as indicated by integration of protons in the $\alpha$-position to oxygen atoms $(3.6-5.0 \mathrm{ppm})$ and of protons in the alkyl chains $(0.8-2.0$ ppm).

Acid hydrolysis of GL-IV yielded a mixture of GDGTs (compounds a-e Fig. 2) and glucose. The glucose purified from the hydrolysate by HPLC had a specific rotation $[\alpha]_{D}^{20}=+52^{\circ}$ establishing its absolute D-configuration.

The ${ }^{13} \mathrm{C}$ NMR signal at $103.5 \mathrm{ppm}$ as well as ${ }^{1} \mathrm{H}$ NMR ignal at $4.35 \mathrm{ppm}\left(\mathrm{J}_{\mathrm{H} 1-\mathrm{H} 2}=7.8 \mathrm{~Hz}\right)$ indicate the presence of a $\beta$-glucosidic linkage. The signal at $62.0 \mathrm{ppm}$ in the ${ }^{13} \mathrm{C}$ NMR spectrum, besides to the C-6 signal of the glucose moiety $(61.8 \mathrm{ppm})$, is due to the free $\mathrm{CH}_{2} \mathrm{OH}$ of the glycerol in the molecule. Glucosyl carbon signal assignments were made by DEPT experiments and by comparison with values reported for methyl $\beta$-D-glucopyranoside $(\mathrm{Ka}$ linowsky et al., 1990) and for related archaeal glycolipids of similar structure (Ferrante et al., 1990).

Comparison of TLC mobilities and of ${ }^{13} \mathrm{C}$ NMR spectrum of GL-IV compound with the glycolipid GL-1 from Thermoproteus tenax, identified as $\beta$-D-glucopyranosyl GDGT (Thurl and Schäfer, 1987) fully confirms its structure as indicated in Fig. 3.

GL-II ( Rf 0.30) is a triglycolipid as indicated by its ${ }^{13} \mathrm{C}$ NMR spectrum in which three anomeric carbons at 103.7, $103.9,104.1 \mathrm{ppm}$ are present, by integration of protons in ${ }^{1} \mathrm{H}$ NMR spectrum and by mild hydrolysis that gave parent GL-III and GL-IV (Fig. 3). Glucose was the sole compound identified in the water phase after acid hydrolysis of this lipid and its absolute D-configuration was determined as above. The downfield glycosylation shift of the C-2 of the glucose of about six ppm $(79.7 \mathrm{ppm})$ indicates that this carbon atom is attached to another glucose molecule as confirmed by methylation analysis. These data are consistent with the $(1 \rightarrow 2)-\beta-D$-glucopyranosyl sequence in the carbohydrate moiety. The Rf of this lipid is similar to that of GL-4 from T. tenax which has however the $(1 \rightarrow 6)-\beta$ D-glucopyranosyl sequence in its sugar head-group (Thurl and Schäfer, 1987).

GPL-II (Rf. 0.16) responds to phosphate reagent. In the ${ }^{13} \mathrm{C}$ NMR spectrum of this compound the downfield shift $(65.3 \mathrm{ppm})$ of the signal at $62.0 \mathrm{ppm}$, indicates the location of a phosphate group on the $\mathrm{CH}_{2} \mathrm{OH}$ of the glycerol; the remaining signals accord with the presence in the molecule of a P-myoinositol and $\beta$-D-glucose (De Rosa et al., 1987; Ferrante et al., 1988).

Acid hydrolysis of GPL-II yielded glucose, P-myolnositol and a mixture of GDGTs (compounds a-e Fig. 2). Selective alkaline hydrolysis of GPL-II, releasing only

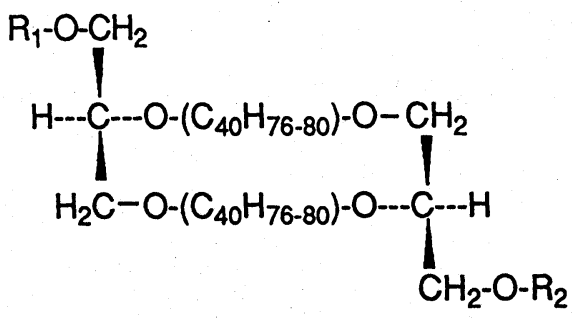

Fig. 3. $\mathrm{R}_{1}$ $\mathbf{R}_{2}$

GLIV $\mathrm{OH}$

GLIII $\mathrm{OH}$

GLII $\mathrm{OH}$

GLPII P-myo-inositol

$\beta$-D-glcp

$\beta$-D-glcp- $(1 \rightarrow 2) \beta$-D-glc $p$

$\beta$-D-glc $p$ - $(1 \rightarrow 2) \beta$-D-glc $p-(1 \rightarrow 2) \beta-D$-glc $p$

GLPI P-myo-inositol $\beta$-D-glc $p$ - $(1 \rightarrow 2) \beta$-D-glc $p-(1 \rightarrow 2) \beta$-D-glc . 
phosphoinositol moiety, gave rise to GL-IV parent glycolipid. TLC comparison with lipids from $T$. tenax shows that GPL-II has the same Rf value of PL-3. These data indicate for GPL-II the structure of Fig. 3.

GPL-I (Rf 0.05) has the same ${ }^{13} \mathrm{C}$ NMR spectrum of GL-II except for the signal at $65.07 \mathrm{ppm}$ assigned to phosphorylated glycerol moiety and for signals of inositol. GPL-I responds to phosphate reagent and alkaline hydrolysis of this lipid gave rise a compound with the same $\mathrm{Rf}$ value of GL-II. The structure of the latter has been assigned as described for GL-II. The comparison with lipids from $T$. tenax indicates that GPL-I has the same Rf as PL-5 which is built up from one tetraether, three glucose residues, one inositol and one phosphate (Thurl and Schäfer, 1987).

\section{Minor complex lipids}

Minor lipids are detected in the pattern of complex lipids of both species of Pyrobaculum. The structures of these minor compounds have been tentatively assigned on the basis of their $\mathrm{Rf}$ values and their response to staining tests and acid hydrolysis.

GL-III (Table 3) has the same Rf value as for the diglucoside GL-3 from T. tenax (Thurl and Schäfer, 1987). Mild hydrolysis of this product gave GL-IV and, at the end of reaction, GDGTs mixture. On the basis of relationship with parent glycolipid GL-IV and GL-II, its structure could be glucopyranosyl ( $1 \rightarrow 2$ )-glucopyranosyl diglycerol tetraether.

Phospholipid (PL-I, Rf 0.20 ) present only in P. organotrophum has the same Rf value as phosphoinositol derivative of GDGT from $S$. solfataricus and after hydrolysis gave GDGTs mixture. GL-I ( $\mathrm{Rf} 0.20$ ) from $P$. islandicum is a tetraether based glycolipid, giving in fact GDGTs mixture after hydrolysis.

\section{Methanococcus genus}

The new isolate Methanococcus igneus Kol5 is a hyperthermophilic methanogen growing up to $92^{\circ} \mathrm{C}$. This organism has been isolated from the Kolbeinsey ridge at a depth of $106 \mathrm{~m}$ in Iceland (Burggraf et al., $1990 \mathrm{~b}$ ). Core lipids of Kol5 are analyzed in comparison with that of Methanococcus jannaschii. Both organisms possess 2,3-diO-phytanyl-sn-glycerol (a, Fig. 1), a macrocyclic diether (b, Fig. 1) identified by EI-MS analysis of acetylated derivative and $[\alpha]_{\mathrm{D}}^{20}$ value, and the uncyclized form of GDGT.

The pattern of complex lipids in both organisms is very complicated as usually found in methanogens. More than 30 spots are present and staining test analysis shows the presence of glyco-, glycophospho-, aminophospho-, and phospholipids.

\section{Discussion}

Several unknown isolates have been analyzed for their lipid composition in comparison with representative members of Archaea domain.
Seven metal-mobilizing organisms have been isolated in Pisciarelli, Agnano (Italy) and in Iceland. They grow from 68 to $80^{\circ} \mathrm{C}$. One of these isolates, the TH2 strain, on the basis of distinct physiological and molecular properties, has been described as type strain of the new genus Metallosphaera (Metallosphaera sedula TH2, DSM 348), while Sp3a can be considered as a strain of the same species (Huber et al., 1989). The analysis of quinone content of the isolates has been particularly useful in that the organisms belonging to the Sulfolobales order all possess benzothiophenquinones instead of naphthoquinone found in halophiles and in other thermophilic organisms (De Rosa and Gambacorta, 1988). All the isolates examined possess the unique caldariellaquinone found so far only in members of the Sulfolobales order. Moreover the analysis of core and complex lipids of these isolates confirms their assignment to this order. In particular the presence of GDNTs is proved to be a very diagnostic tool in ascribing new organisms to the Sulfolobales order.

Archaeoglobus may represent a biochemical missing link between methanogens and sulfur-metabolizing archaea. This genus is represented by the type species Archaeoglobus fulgidus, isolated from a shallow marine hydrothermal system at Vulcano, Italy. Recently the strain AV18, isolated from Guaymas hot vent areas, has been classified as a new species of Archaeoglobus genus and named profundus (DSM 5681). Although core lipids of this new species are the same of those found in the parent species $A$. fulgidus, complex lipids show the differences confirming the assignment of the isolate AV18 as a new species. Biochemical data about the isolate Kol3, possessing the same complex lipid pattern of AV18, are not available until now.

Three genera belong to Thermoproteales order, Thermoproteus, Pyrobaculum and Thermofilum. A detailed complex-lipid characterization is reported for Pyrobaculum islandicum and P. organotrophum. A close relationship at level of complex lipids is found between $T$. tenax and Pyrobaculum species. In fact both polar head(s) and core lipid(s) are the same (phosphomyoinositol, $\beta$-Dglucose, GDGTs mixture) being the sole difference the se -quence of carbohydrate in the di- and triglycolipids. No data on complex lipids of Thermofilum species are at moment available. Although a close similarity of complex and core lipids in the Thermoproteales order exists, a fine structural definition of complex lipids clearly shows differences among different genera of the same order. Moreover, from a structural point of view, as previously stated for T. tenax and in general as seen for other archaea, also in Pyrobaculum a biosynthetic relationship between glycolipids and phosphoglycolipids could exist.

Within Methanococcus genus the presence of macrocyclic diether (b, Fig. 1) has been reported so far only in the lipids of the species Mc. jannaschii. This is the first report of a new recognized organism, assigned to the genus Methanococcus, possessing this diether.

Acknowledgments. The authors thank Mr. Edoardo Pagnotta and Mrs. Ida Romano for their skillfull assistance, Mr. Raffaele Turco for art work and NMR service of ICMIB. 


\section{- References}

Achenbach-Richter, L., Stetter, K. O., Woese, C. R.: A possible biochemical missing link among archaebacteria. Nature 327 , 348-349 (1987)

Allen, M. B.: Studies with Cyanidium caldarium, an anomalously pigmented chlorophyte. Arch. Mikrobiol. 32, 270-277 (1959)

Balch, W. E., Fox, G. E., Magrum, L. J., Woese, C. R., Wolfe, R. S.: Methanogens: reevaluation of a unique biological group. Microbiol. Rev. 43, 269-296 (1979)

Burggraf, S., Jannasch, H. W., Nicolaus, B., Stetter, K. O.: Archaeoglobus profundus sp. nov., represents a new species within the sulfate-reducing archaebacteria. System. Appl. Microbiol. 13, 24-28 (1990 a)

Burggraf, S., Fricke, H., Neuner, A., Kristjansson, J., Rouvier, P., Mandelco, L., Woese, C. R., Stetter, K. O.: Methanococcus igneus sp. nov., a novel hyperthermophilic methanogen from a shallow submarine hydrothermal. System. Appl. Microbiol. 13, 263-269 (1990 b)

Comita, P. B., Gagosian, R. B., Pang, H., Costello, C. E.: Structural elucidation of a unique macrocyclic membrane lipid from a new, extremely thermophilic, deep-sea hydrothermal vent archaebacterium, Methanococcus jannaschii. J. Biol. Chem. 259, 15234-15241 (1984)

De Rosa, M., Gambacorta, A.: The lipids of archaebacteria. Prog. Lipid Res. 27, 153-175 (1988)

De Rosa, M., Gambacorta, A., Nicolaus, B., Chappe, B., Albrecht, $P$. .: Isoprenoid ethers: backbone of complex lipids of the archaebacterium Sulfolobus solfataricus. Biochim. Biophys. Acta 753, 248-256 (1983)

De Rosa, M., Gambacorta, A., Trincone, A., Basso, A., Zillig, W., Holz, I.: Lipids of Thermococcus celer a sulfur-reducing archaebacterium: structure and biosynthesis. System. Appl. Microbiol. 9, 1-5 (1987)

De Rosa, M., Lanzotti, V., Nicolaus, B., Trincone, A., Gambacorta, A.: Lipids of archaeobacteria: structural and biosynthetic aspects, pp.131-151. In: Microbiology of extreme environments and its potential for biotechnology (M.S. Da Costa, J. C. Duarte, R. A. D. Williams, eds.). New York, Elsevier Applied Science 1989

De Rosa, M., Trincone, A., Nicolaus, B., Gambacorta, A.: Archaebacterial lipids: membrane structures and adaptation to environmental stresses, pp. 61-87. In: Life under extreme conditions (G. Di Prisco, ed.). Berlin, Springer Verlag 1991

Jittmer, J. C., Lester, R. L.: A simple, specific spray for the detection of phospholipids on thin-layer chromatograms. J. Lipid Res. 5, 126-127 (1964)

Ferrante, G., Ekiel, I., Girischandra, B. P., Sprott, G. D. E.: Structure of the major polar lipids isolated from the aceticlastic methanogen Methanotrix concilli GP6. Biochim. Biophys. Acta 963, 162-172 (1988)

Ferrante, G., Richards, J. C., Sprott, G. D.: Structures of polar lipids from the thermophilic, deep-sea archaebacterium Methanococcus jannaschii. Biochim. Cell. Biol. 68, 274-283 (1990)

Huber, G., Spinnler, C., Gambacorta, A., Stetter, K. O.: Metallosphaera sedula gen. and sp. nov. represents a new genus of aerobic, metal-mobilizing, thermoacidophilic archaebacteria. System. Appl. Microbiol. 12, 38-47 (1989)
Huber, R., Kristjansson, J. K., Stetter, K. O.: Pyrobaculum gen. nov., a new genus of neutrophilic, rodshaped archaebacteria from continental solfataras growing at $100 \mathrm{C}$. Arch. Mikrobiol. 149, 95-101 (1987)

Huber, R., Huber, G., Segerer, A., Seger, J., Stetter, K. O.: Aerobic and anaerobic extremely thermophilic autotrophs, pp. 44-51. In: Microbial growth on $\mathrm{C}_{1}$ compounds $(H$. W. Van Verseveld, J. A. Daine, eds.). Proc. 5th Int. Symp. Martinus Nijoff, Dordrecht 1987

Kalinowsky, H. O., Berger, S., Braun, S.: Carbon-13 NMR spectroscopy, pp. 441. New York, Wiley 1990

Kates, M.: Ether linked lipids in extremely halophilic bacteria, pp. 351-398. In: Ether lipids, chemistry and biology, (F. Snyder, ed.). New York, Academic Press 1972

Segerer, A., Stetter, K. O., Klink, F.: Two contrary modes of chemolithotrophy in the same archaebacterium. Nature 313, 787-789 (1985)

Segerer, A., Neuner, A., Kristjansson, J. K., Stetter, K. O.: Acidianus infernus gen. nov., sp. nov., and Acidianus brierleyi comb. nov.: facultatively aerobic, extremely acidophilic thermophilic sulfur-metabolizing archaebacteria. Int. J. System. Bact. 36, 559-564 (1986)

Stetter, K. O., Lauerer, G., Thomm, M., Neuner, A.: Isolation of extremely thermophilic sulfate reducers: evidence for a novel branch of archaebacteria. Science 236, 822-824 (1987)

Stetter, K. O.: Archaeoglobus fulgidus gen. nov., sp. nov. A new taxon of extremely thermophilic archaebacteria. System. Appl. Microbiol. 10, 172-173 (1988)

Stetter, K. O., Fiala, G., Huber, G., Huber, R., Segerer, A.: Hyperthermophilic microorganisms. FEMS Microbiol. Rev. 75, 117-124 (1990)

Thurl, S., Schäfer, W.: Lipids from the sulfur-dependent archaebacterium Thermoproteus tenax. Biochim. Biophys. Acta 961, 253-261 (1987)

Trincone, A., De Rosa, M., Gambacorta, A., Lanzotti, V., Nicolaus, B., Harris, J. E., Grant, W. D.: A simple chromatographic procedure for the detection of cyclized archaebacterial glycerol-bisdiphytanyl-glycerol tetraether core lipids. J. Gen. Microbiol. 134, 3159-3163 (1988)

Trincone, A., Lanzotti, V., Nicolaus, B., Zillig, W., De Rosa, M., Gambacorta, A.: Comparative lipid composition of aerobically and anaerobically grown Desulfurolobus ambivalens, an autotrophic thermophilic archaebacterium. J. Gen. Microbiol. 135, 2751-2757 (1989)

Woese, C. R., Magrum, L. J., Fox, G. E.: Archaebacteria. J. Mol. Evol. 11, 245-252 (1978)

Woese, C. R., Kandler, O., Wheelis, M. L.: Towards a natural system of organisms. Proposal for the domains archaea, bacteria, and eucarya. Proc. Natl. Acad. Sci. USA 87, 4576-4579 (1990)

Yahara, S., Kasai, R., Tanaka, O.: New Dammarane Type Saponins of laeves of Panax japonicus C. A. Meyer. 1. Chikusetsusaponins- $\mathrm{L}_{5},-\mathrm{L}_{9 \mathrm{a}}$ and $-\mathrm{L}_{10}$. Chem. Pharm. Bull. 25, 2041-2047 (1977)

Zillig, W., Yeats, S., Holz, J., Bock, A., Rettenberger, M., Gropp, F., Simon, G.: Desulfurolobus ambivalens gen. nov. sp. nov., an autrotrophic archaebacterium facultatively oxidizing or reducing sulfur. System. Appl. Microbiol. 8, 197-203 (1986) 